\title{
AVALIAÇÃO DE ESPÉCIES VEGETAIS NA FITORREMEDIAÇÃO DE SOLOS CONTAMINADOS POR METAIS PESADOS
}

\author{
S. R. L. TAVARES ${ }^{1}$; S. A. OLIVEIRA ${ }^{2}$ \& C. M. SALGADO ${ }^{3}$ \\ ${ }^{1}$ Empresa Brasileira de Pesquisa Agropecuária (EMBRAPA SOLOS) \\ ${ }^{2}$ Universidade Federal do Rio de Janeiro (COPPE/UFRJ) \\ ${ }^{3}$ Universidade Federal Fluminense (Departamento de Geografia/UFF) \\ silvio.tavares@embrapa.br
}

Artigo submetido em novembro/2013 e aceito em dezembro/2013

\section{RESUMO}

O presente trabalho teve por objetivo avaliar o comportamento de diferentes espécies vegetais cultivadas em solo contaminado por metais pesados. Para a realização do experimento em casa de vegetação coletou-se um solo que corresponde a um aterramento de Argissolo Vermelho-Amarelo proveniente de uma área industrial (resíduo de lodo galvânico) no estado do Rio de Janeiro. Esse solo teve suas propriedades químicas e físicas determinadas. Por um período de 50 dias foram cultivadas as espécies de algodão, milho, sorgo, girassol e mucuna nesse solo contaminado. Transcorrido o período de plantio, avaliou-se a produção de massa seca da parte aérea, colmo e sistema radicular de cada espécie estudada, assim como, os teores de metais pesados absorvido nesses diferentes compartimentos. Os teores pseudo-totais (extração por água-régia) e biodisponíveis (extração por solução de DTPA e Mehlich-1) dos metais pesados presentes no solo foram determinados antes e após o plantio das espécies. O delineamento estatístico utilizado no estudo foi inteiramente casualizado, com quatro repetições para cada espécie investigada. Os resultados indicaram que as espécies apresentaram comportamento bem diferenciado quanto à produção de biomassa, absorção e translocação dos metais para parte aérea. O girassol destacou-se em relação às demais espécies em reduzir a concentração do metal cobre no solo, embora mais estudos devam ser realizados, visando aumentar a produção de biomassa e a translocação dos metais pesados para parte aérea desta espécie.

PALAVRAS-CHAVE: remediação do solo, recuperação de áreas degradadas, área contaminada

\section{USE OF DIFFERENT SOURCES OF BIOMASS PLANT FOR THE PRODUCTION OF SOLID BIOFUEL}

\begin{abstract}
This study aimed to evaluate the behavior of different plant species grown in soil contaminated by heavy metals. For realization the experiment in greenhouse we collected a soil that corresponds to a grounding Ultisol, located in the State of Rio de Janeiro, in an area considered contaminated, which is headquartered in a factory that generates its industrial process, waste, called Galvanic sludge. This soil had its chemical and physical properties determined. For a period of 50 days were cultivated species of cotton, corn, sorghum, sunflower and velvetbean in contaminated soil. After the period of planting, we evaluated the dry matter production of shoots, stems and roots of each species studied, as well as the concentrations of heavy metals
\end{abstract}

absorbed in these different compartments. The pseudototal content (aqua regia extraction) and bioavailable (DTPA extraction solution and Mehlich-1) of heavy metals in the soil were determined before and after planting the species. The statistical design used in the study was completely randomized with four replications for each species investigated. The results showed that the species behaved well differentiated in biomass production, uptake and translocation of metals to shoots. The sunflower stood out compared to the other species in reducing the concentration of copper metal in the soil, although more studies should be conducted in order to increase biomass production and translocation of heavy metals to shoots of this species

KEYWORDS: soil remediation, recuperation of degraded areas, contaminated area 


\section{AVALIAÇÃO DE ESPÉCIES VEGETAIS NA FITORREMEDIAÇÃO DE SOLOS CONTAMINADOS POR METAIS PESADOS}

\section{INTRODUÇÃO}

A preocupação com o desenvolvimento de estudos na área ambiental está crescendo a cada dia. Pesquisas realizadas em locais próximos aos complexos industriais têm indicado concentrações elevadas de metais pesados no solo, no qual afetam a produtividade, sustentabilidade e biodiversidade dos ecossistemas (SOARES et al., 2002). Solos que se encontram nessas condições exigem ação remediadora que diminua os teores desses poluentes em níveis ambientalmente seguros.

Para a remediação de solos contaminados por metais pesados, diversas técnicas têm sido propostas. Essas tecnologias são muito variáveis, conforme a matriz contaminada, a natureza do contaminante, o nível de contaminação e a disponibilidade de recursos. No presente estudo foi dado ênfase a técnica de fitorremediação, que faz uso de plantas e seus microrganismos associados, visando o tratamento in situ de solos contaminados (TAVARES, 2009). Essa tecnologia apresenta como principais vantagens o baixo custo e a possibilidade de aplicação em áreas extensas, além de ser uma técnica de remediação in situ, não provocando contaminações secundárias. Essa técnica também promove a revegetação de áreas contaminadas, que ajuda a proteger o solo contra a erosão eólica e hídrica, ao mesmo tempo em que melhora esteticamente a área degradada.

Na fitorremediação, as plantas auxiliam removendo, contendo, transferindo, estabilizando e tornando inofensivos os metais pesados presentes no solo. A fitorremediação envolve diferentes métodos, entre eles estão a fitoextração e a fitorremediação. A fitoextração emprega plantas hiperacumuladoras para remover os metais do solo pela absorção e acúmulo nas raízes e na parte aérea das plantas, que poderão ser posteriormente dispostas em aterros sanitários ou recicladas para a recuperação do metal. Estas plantas são capazes de tolerar, absorver e translocar altos níveis de determinados metais pesados que seriam tóxicos a qualquer outro organismo (ZEITOUNI, 2003). A fitoestabilização consiste no uso de plantas para imobilizar contaminantes no sistema solo-planta, visando reduzir a biodisponibilidade destes e prevenir sua entrada nas águas subterrâneas ou na cadeia alimentar (ACCIOLY E SIQUEIRA, 2000).

É desejável que no processo de fitorremediação as espécies vegetais apresentem um crescimento rápido, elevada produção de biomassa, competitividade, vigor e tolerância à poluição (LAMEGO \& VIDAL, 2007). Deste modo, faz-se necessário o desenvolvimento de estudos, com o intuito de selecionar um número expressivo de espécies vegetais (herbáceas, arbóreas e arbustivas) com potencial de atuarem como fitorremediadoras de áreas contaminadas por metais pesados. Este trabalho teve por objetivo principal avaliar o comportamento de diferentes espécies vegetais na fitorremediação de solo contaminado por metais pesados, e especificamente:

- Determinar os níveis de metais pesados no solo da área contaminada;

- Analisar as propriedades químicas e físicas do solo da área contaminada;

- Determinar a produção de matéria seca das espécies cultivadas no solo contaminado; 
- Determinar os teores de metais pesados na partição (parte aérea, colmo e sistema radicular) das diferentes espécies avaliadas;

- Avaliar a eficiência de extratores químicos na determinação e interpretação dos resultados analíticos;

- Determinar as concentrações dos metais pesados no solo após o período de plantio das espécies.

\section{MATERIAIS E MÉTODOS}

O presente estudo foi desenvolvido em casa-de-vegetação localizada nas dependências da sede da Embrapa Solos-RJ. No experimento foi utilizado um aterramento de Argissolo VermelhoAmarelo, de aproximadamente $130 \mathrm{~cm}$ de espessura no topo do horizonte $A$, coletado no Estado do Rio de Janeiro, em uma área considerada contaminada, onde está sediada uma fábrica que gera em seu processo industrial, resíduo, denominado Lodo Galvânico.

O solo coletado, em uma profundidade média de $20 \mathrm{~cm}$, foi seco em estufa, destorroado, peneirado em ( $2 \mathrm{~mm}$ ) e suas propriedades químicas e físicas caracterizadas de acordo com a metodologia EMBRAPA (2009), conforme descrito a seguir.

\section{- Potencial hidrogeniônico (pH)}

Medição do potencial eletronicamente por meio de eletrodo combinado imerso em suspensão sólido: líquido $\left(\mathrm{H}_{2} \mathrm{O}\right.$ e $\left.\mathrm{KCl}\right)$ na proporção 1:2,5. Para isso utilizou-se potenciômetro de bancada, marca Orion, modelo $710 \mathrm{~A}$ com eletrodo de vidro combinado, da marca Analion.

\section{- $\quad$ Capacidade de troca catiônica (CTC)}

A capacidade de troca catiônica (CTC) dos solos determinada por esse método consitiu na extração das bases trocáveis de cálcio $\left(\mathrm{Ca}^{2+}\right)$ e magnésio $\left(\mathrm{Mg}^{2+}\right)$ com solução de $\mathrm{KCl}(\mathrm{N})$ e de sódio $\left(\mathrm{Na}^{+}\right)$e potássio $\left(\mathrm{K}^{+}\right)$com solução de Mehlich-1, seguida da leitura dos elementos $\mathrm{Ca}^{2+} \mathrm{e} \mathrm{Mg}^{2+}$ em Espectrômetro de Emissão Atômica com Plasma Induzido (ICP-OES), da marca Perkin Elmer,

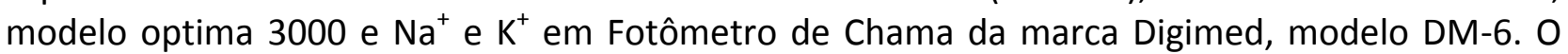
Alumínio trocável $\left(\mathrm{Al}^{3+}\right)$ foi obtido através de extração com solução de $\mathrm{KCl}(\mathrm{N})$ e determinação volumétrica com solução diluída de $\mathrm{NaOH}$. A acidez potencial $\left(\mathrm{H}^{+}+\mathrm{Al}^{3+}\right)$ foi determinada por meio de extração com solução de acetato de cálcio tamponado a $\mathrm{pH} 7,0 \mathrm{em}$ presença do indicador fenolftaleína e titulação com solução de $\mathrm{NaOH}$.

\section{- Carbono orgânico}

A matéria orgânica foi oxidada com dicromato de potássio em meio sulfúrico, utilizandose como fonte de energia o calor desprendido do ácido sulfúrico e/ou aquecimento. 0 excesso de dicromato foi titulado com sulfato ferroso amoniacal (sal de Mohr).

\section{- Nitrogênio}

O nitrogênio foi convertido em sulfato de amônio através de oxidação com uma mistura de $\mathrm{CuSO}_{4}, \mathrm{H}_{2} \mathrm{SO}_{4}$ e $\mathrm{Na}_{2} \mathrm{SO}_{4}$. 


\section{- Análise granulométrica}

Para a realização da análise foi utilizado o método do densímetro. Esse método teve como base a sedimentação das partículas que compõem o solo. Após a adição de um dispersante químico $(\mathrm{NaOH})$, fixou-se um tempo único para a determinação da densidade da suspensão, que se admitiu ser a concentração total de argila. As frações grosseiras (areias fina e grossa) foram separadas por tamisação e pesadas. O silte foi obtido por diferença.

\section{- Densidade do solo}

Foi utilizado o método da proveta, que consistiu na determinação do peso de solo compactado necessário para completar o volume de uma proveta de $100 \mathrm{~mL}$.

- Densidade de partículas

Essa análise foi realizada determinando-se o volume de álcool necessário para completar a capacidade de um balão volumétrico, contendo solo seco em estufa.

- Porosidade total

Foi determinado o volume de poros totais do solo ocupados por água e/ou ar.

\section{AVALIAÇÃO DOS METAIS PESADOS NOS SOLOS}

Para a determinação dos metais pesados presentes nos solos foram utilizados os métodos Mehlich-1 (MEHLICH, 1953) e DTPA (LINDSAY \& NORVELL, 1978) para a determinação dos teores biodisponíveis, e o método Água Régia (BERROW \& STEIN, 1983) para a quantificação dos teores pseudo-totais. Esses métodos estão descritos de forma mais detalhada abaixo.

\section{TEORES BIODISPONÍVEIS}

\section{- DTPA}

Foram pesados 10,000g de Terra Fina Seca ao Ar (TFSA), de cada solo, em frascos cônicos de polietileno e adicionou-se $20 \mathrm{ml}$ de solução extratora DTPA (DTPA 0,005 mol..-1 + TEA 0,1 mol. $\mathrm{L}^{-1}+\mathrm{CaCl}_{2}$ 0,01 mol. $\left.\mathrm{L}^{-1}, \mathrm{pH} 7,3\right)$. Em seguida a mistura foi agitada por duas horas a $220 \mathrm{rpm}$ em agitador mecânico orbital e filtrada imediatamente a suspensão. As concentrações dos metais pesados foram determinadas em Espectrômetro de Emissão Atômica com Plasma Induzido (ICP-OES), modelo OPTIMA 3000- Perkin-Elmer da Embrapa Solos.

\section{- MEHLICH-1}

Foram pesados $5,000 \mathrm{~g}$ de TFSA, de cada solo, em frascos cônicos de polietileno e adicionou-se $25 \mathrm{ml}$ de solução extratora de Mehlich-1 ( $\mathrm{HCl}$ 0,05 mol.L ${ }^{-1}+\mathrm{H}_{2} \mathrm{SO}_{4}$ 0,0125 mol.L $\left.{ }^{-1}\right)$. Em seguida a mistura foi agitada por cinco minutos a $220 \mathrm{rpm}$ em agitador mecânico orbital e filtrada imediatamente a suspensão. As concentrações dos metais pesados foram determinadas em Espectrômetro de Emissão Atômica com Plasma Induzido (ICP-OES), modelo OPTIMA 3000Perkin-Elmer da Embrapa Solos. 


\section{TEORES PSEUDO-TOTAI}

\section{- $\quad$ Água régia}

Esse método consistiu no emprego de mistura ácida 3:1 (ácido clorídrico/ácido nítrico). Deste modo, foram pesados $0,2500 \mathrm{~g}$ de TFSA e transferidos para tubos teflon, onde foram adicionados $9 \mathrm{ml}$ de $\mathrm{HCL}(37 \%)$ e $3 \mathrm{ml}$ de $\mathrm{HNO}_{3}$ (65\%). A mistura foi deixada em repouso por 10 minutos e, em seguida, os frascos foram fechados e levados para o forno de microondas, sendo a seguinte programação utilizada: Potência: 1200 w; Pressão: 0,5 bar.s ${ }^{-1}$; Temperatura na rampa: 1400 C em 5' 30"; Tempo de permanência a 1400 C no platô: 15'00' e Tempo de resfriamento $20^{\prime} 00^{\prime \prime}$. Após o término da programação, os frascos foram abertos em capelas de exaustão e a solução transferida para frascos cônicos de polietileno, sendo complementado o volume para 30 $\mathrm{mL}$ com água ultra pura. As concentrações dos metais pesados foram determinadas por Espectrômetro de Emissão Atômica com Plasma Induzido (ICP-OES), modelo OPTIMA 3000Perkin-Elmer da Embrapa Solos.

Como parte dos protocolos analíticos para determinação dos metais pesados de interesse, o controle da qualidade analítica é essencial para assegurar a confiabilidade dos resultados obtidos e como parte da validação dos métodos. Neste estudo, foram utilizados os seguintes materiais de referência certificados: MRC 2709 - San Joaquim Soil (metais em solos); MRC 2710 Montana Soil (teor elevado de traços de metais) e o MRC 2711 - Montana Soil (teor moderado de traços de metais).

Todas as curvas analíticas dos metais pesados analisados pelo ICP-OES tiveram coeficientes de correlação R2 > 0,995. Todas essas determinações foram acompanhadas de provas em branco (Blank) e triplicatas para as amostras, materiais de referência certificados e padrões aquosos para os metais analisados. O comprimento de onda e o limite de detecção dos elementos analisados pelo plasma ótico (ICP) podem ser visualizados na tabela 1.

Tabela 1: Comprimento de onda $(\mathrm{nm})$ e limite de detecção $\left(\mathrm{mg} \cdot \mathrm{L}^{-1}\right)$ dos elementos analisados em Espectrômetro de Emissão Atômica com Plasma Induzido (ICP-OES):

\begin{tabular}{ccc}
\hline Elemento & $\begin{array}{c}\text { Comprimento de Onda } \\
(\mathbf{n m})\end{array}$ & $\begin{array}{c}\text { Limite de detecção } \\
\left(\mathbf{m g}^{-\mathbf{L}^{-1}}\right)\end{array}$ \\
\hline $\mathbf{C a}$ & 317.933 & 0,030 \\
$\mathbf{M g}$ & 279.079 & 0,020 \\
$\mathbf{A l}$ & 308.215 & 0,035 \\
$\mathbf{C u}$ & $324.754 / 327.396$ & 0,003 \\
$\mathbf{F e}$ & $238.204 / 259.940$ & 0,040 \\
$\mathbf{M n}$ & 257.610 & 0,001 \\
$\mathbf{Z n}$ & $213.856 / 206.191$ & 0,001 \\
$\mathbf{C r}$ & $205.560 / 267.716$ & 0,007 \\
$\mathbf{C o}$ & 228.616 & 0,007 \\
$\mathbf{N i}$ & $232.003 / 231.604$ & 0,020 \\
$\mathbf{C d}$ & $214.438 / 226.502$ & 0,002 \\
$\mathbf{P b}$ & 220.353 & 0,040 \\
\hline
\end{tabular}

\section{EXPERIMENTO DE FITORREMEDIAÇÃO}

Para a realização deste experimento foi utilizado o solo contaminado acima citado, que após seco em estufa teve suas propriedades químicas, físicas e teores de metais pesados determinados. 
Para a montagem do experimento foram pesados $1,5 \mathrm{~kg}$ de solo em vasos de polietileno, perfazendo um total de 20 unidades experimentais. Esses vasos foram mantidos em ambiente controlado em casa-de-vegetação da Embrapa-Solos (RJ). Posteriormente, foram plantadas mudas de sorgo (Sorghum bicolor), milho (Zea mays), algodão (Gossypium hirsutum L.), girassol (Helianthus annuus) e mucuna (Mucuna pruriens) em cada vaso, com quatro repetições para cada espécie avaliada, constituindo um total de cinco tratamentos. Durante o plantio das espécies, os vasos foram irrigados com água destilada, de modo a não ultrapassar o limite máximo de $70 \%$ da capacidade de campo deste solo. Em intervalos semanais os vasos eram irrigados com $50 \mathrm{ml}$ de solução nutritiva.

Sucedido o período de 50 dias de plantio das espécies, foram coletadas dos vasos suas biomassas, que foram segregadas em parte aérea, colmo e sistema radicular. As plantas cortadas foram lavadas, acondicionadas em sacos de papel e secas em estufas de ar com circulação forçada à temperatura entre 65 e $70^{\circ} \mathrm{C}$ até atingir o peso constante. Depois de secas, as partes da planta (parte aérea, colmo e sistema radicular) foram pesadas para a determinação da biomassa e, em seguida, moídas em moinho da marca IKA, modelo A11, do Laboratório de Análises de Solos e Plantas (LASP) da Embrapa Solos. Depois de moídas, as partes das plantas foram acondicionadas em recipiente de polietileno e direcionadas para análises, com o objetivo de se obter o estado nutricional desta, assim como, determinar os teores de metais pesados fitoextraídos.

Transcorrido o procedimento de coleta das plantas, cerca de $200 \mathrm{~g}$ de amostras de solo foram retiradas de cada vaso e direcionadas para secagem em estufa de circulação de ar forçada a $105^{\circ} \mathrm{C}$ até a secagem homogênea. Essas amostras foram passadas em peneira de náilon (malha de $2 \mathrm{~mm}$ ) e encaminhadas para análises de determinação dos teores biodisponíveis e pseudototais dos metais pesados de interesse.

\section{ANÁLISES DO TECIDO VEGETAL}

A biomassa vegetal (parte aérea, colmo e sistema radicular) foi submetida à digestão nitroperclórica por via úmida (sistema aberto). O procedimento analítico consistiu em pesar $0,500 \mathrm{~g}$ de cada amostra vegetal em tubo de digestão. Em seguida, foram adicionados $4 \mathrm{~mL}$ de $\mathrm{HNO}_{3}(65 \%)$ nos tubos, que ficaram em repouso por $24 \mathrm{hs}$. Posteriormente, os tubos foram aquecidos em bloco digestor a $90^{\circ} \mathrm{C}$ nos primeiros 30 minutos e a $120^{\circ} \mathrm{C}$ até que restasse $0,5-$ $1,0 \mathrm{~mL}$ da mistura nos tubos. Após o processo de resfriamento dos tubos por aproximadamente 10 minutos, foram adicionados nos tubos $2,0 \mathrm{~mL}$ de $\mathrm{HClO}_{4}(70 \%)$ que foi mantido sob aquecimento a $190^{\circ} \mathrm{C}$ até que o material tivesse totalmente digerido. Essas amostras após serem digeridas foram transferidas para tubos do tipo falcon e avolumadas para $30 \mathrm{ml}$. As determinações dos teores de $\mathrm{Zn}, \mathrm{Cr}, \mathrm{Co}, \mathrm{Ni}, \mathrm{Cd}, \mathrm{Pb}$ e $\mathrm{P}$ foram obtidas por meio do ICP-OES e os teores de $\mathrm{K}$ e Na por meio de Fotômetro de Chama, da marca Digimed, modelo DM-61 do LASP da Embrapa Solos.

A quantificação do teor de nitrogênio no tecido vegetal foi avaliada pelo método de destilação e titulação Kjeldahl (EMBRAPA, 2009). As amostras após serem digeridas em ácido sulfúrico $\left(\mathrm{H}_{2} \mathrm{SO}_{4}\right)$ foram destiladas em meio fortemente alcalino, utilizando o destilador da marca Velp Scientifica, modelo UDK 142 do LASP da Embrapa Solos. $\mathrm{O} \mathrm{NH}^{4+}$ condensado foi coletado na solução de $\mathrm{H}_{3} \mathrm{BO}_{3}$ e titulado com solução de $\mathrm{HCl}$ em bureta automática da marca Metrohm, modelo 776 Dosimat do LASP da Embrapa Solos. 
Como parte dos protocolos analíticos foram utlizadas amostras certificadas do Programa Interlaboratorial de Análise de Tecido Vegetal (ESALQ/USP) do ano 23 (biênio 2008-2009), de forma a assegurar uma maior precisão nos resultados das análises realizadas.

\section{MÉTODOS ESTATÍSTICOS}

O delineamento experimental utilizado neste experimento foi inteiramente casualizado. Todos os parâmetros estudados foram submetidos, antes das análises estatísticas paramétricas usuais, ao teste de Lilliefors (que é uma derivação do teste de Kolmogorov-Smirnov), para verificar se os valores de dados de uma determinada variável seguem ou não uma distribuição de médias e desvios-padrão calculados na mesma amostra (se eles têm distribuições normais). Os dados também foram submetidos aos testes de Cochran que é usado para verificação da homogeneidade de variâncias.

Os dados foram agrupados em planilhas eletrônicas e, posteriormente, calculados os resíduos no software SAS e aplicados os teste de homogeneidade de variância, segundo os procedimentos de Cochran / Bartlet e normalidade pelo teste de Lilliefors com o uso do software SAEG 9.1. Em seqüência, os dados foram submetidos à análise de variância e comparados por teste de confrontamento de médias (Turkey a $5 \%$ de probabilidade), utilizando o pacote estatístico SISVAR versão 5.1. Os resultados finais foram ordenados através de tabelas e gráficos para uma melhor visualização do comportamento das espécies em fitoextrair os metais pesados do solo contaminado.

\section{RESULTADOS E DISCUSSÃO}

\section{ANÁLISE DO SOLO}

No presente estudo foi utilizado um solo contaminado, coletado em uma área industrial do Estado do Rio de Janeiro. Esse solo trata-se de um aterramento de Argissolo VermelhoAmarelo, de aproximadamente $130 \mathrm{~cm}$ de espessura no topo do horizonte A. Para uma melhor compreensão da dinâmica dos metais pesados no solo tornou-se imperativo determinar as propriedades químicas e físicas deste solo, conforme pode ser visualizado nas tabela 2 .

Tabela 2 - Propriedades físicas e químicas do solo utilizado:

\begin{tabular}{|c|c|c|c|}
\hline \multicolumn{2}{|c|}{ Propriedades Físicas } & \multicolumn{2}{|c|}{ Propriedades Químicas } \\
\hline Atributos & $\begin{array}{c}\text { Valor no solo } \\
\text { do aterro }\end{array}$ & Atributos & $\begin{array}{c}\text { Valor no solo } \\
\text { do aterro }\end{array}$ \\
\hline Calhaus (>20mm) (\%) & - & $\mathrm{pH}$ em $\mathrm{H}_{2} \mathrm{O}(1: 2,5)$ & 7,6 \\
\hline Cascalho (2-20mm) (\%) & - & $\mathrm{pH}$ em $\mathrm{KCl}(1 \mathrm{M})$ & 7,5 \\
\hline Terra Fina $(<2 \mathrm{~mm})(\%)$ & 100,0 & $\mathrm{P}\left(\mathrm{mg} \cdot \mathrm{kg}^{-1}\right)$ & 7,0 \\
\hline Argila (\%) & 32,5 & $\mathrm{Na}\left(\mathrm{cmol}_{\mathrm{c}} \cdot \mathrm{kg}^{-1}\right)$ & 0,1 \\
\hline Silte (\%) & 23,8 & $\mathrm{~K}\left(\mathrm{cmol}_{\mathrm{c}} \cdot \mathrm{kg}^{-1}\right)$ & 0,3 \\
\hline Areia Grossa (\%) & 33,1 & $\mathrm{Ca}\left(\mathrm{cmol}_{\mathrm{c}} \cdot \mathrm{kg}^{-1}\right)$ & 5,1 \\
\hline Areia Fina (\%) & 10,6 & $\mathrm{Mg}\left(\mathrm{cmol}_{\mathrm{c}} \cdot \mathrm{kg}^{-1}\right)$ & 0,8 \\
\hline Densidade Aparente (g. $\mathrm{cm}^{3}$ ) & 1,31 & $\mathrm{H}+\mathrm{Al}\left(\mathrm{cmol}_{\mathrm{c}} \cdot \mathrm{kg}^{-1}\right)$ & 0,0 \\
\hline Densidade Real (g.cm3) & 2,62 & $\mathrm{~S}\left(\mathrm{cmol}_{\mathrm{c}} \cdot \mathrm{kg}^{-1}\right)$ & 6,3 \\
\hline Porosidade (\%) & 50,0 & $\mathrm{~T}\left(\mathrm{cmol}_{\mathrm{c}} \cdot \mathrm{kg}^{-1}\right)$ & 6,3 \\
\hline Grau de Floculação (\%) & 100,0 & $\mathrm{~V}(\%)$ & 100,0 \\
\hline Argila Dispersa em Água (\%) & 0,0 & $\mathrm{C}_{\text {orgânico }}\left(\mathrm{g} \cdot \mathrm{kg}^{-1}\right)$ & 4,7 \\
\hline- & - & $\mathrm{N}\left(\mathrm{g} \cdot \mathrm{kg}^{-1}\right)$ & 0,6 \\
\hline- & - & $\mathrm{C} / \mathrm{N}$ & 7,8 \\
\hline- & - & Equivalente de $\mathrm{CaCO}_{3}\left(\mathrm{~g} \cdot \mathrm{kg}^{-1}\right)$ & - \\
\hline
\end{tabular}


Ao observar as características físicas do aterro, observa-se que a classificação textural deste solo é FRANCO- ARGILO- ARENOSO (LEMOS \& SANTOS, 1984). Essa classificação é importante, pois nos indica alguns aspectos quanto à mobilidade dos metais pesados no solo. Via de regra, quanto mais alto o conteúdo de argila, maior é a troca catiônica (em qualquer valor de $\mathrm{pH}$ ) e menor a mobilidade do metal no solo. Logo, pode-se inferir que a contaminação de metais pesados neste perfil pode ter comportamento de mobilidade alta nos primeiros centímetros de profundidade.

Outro importante atributo do solo na mobilidade dos metais pesados é o $\mathrm{pH}$, visto que está positivamente correlacionado com a adsorção de metais no solo (McBRIDE \& BLASIAK, 1979). A disponibilidade dos metais pesados é relativamente baixa em valores de $\mathrm{pH}$ ao redor de 6,5 a 7 (KABATA-PENDIAS \& PENDIAS, 2001); a mobilidade dos metais pesados na maioria dos solos diminui com o aumento do $\mathrm{pH}$ para valores próximos à neutralidade, em virtude da precipitação de formas insolúveis, como hidróxidos, carbonatos e complexos orgânicos. Para o solo em estudo foi observado que o pH ficou na faixa da neutralidade para alcalinidade.

O resultado referente ao complexo sortivo indicou um valor elevado para saturação de bases não aparecendo em nenhuma análise à presença de $\mathrm{Al}^{3+}$ nem de $\mathrm{H}^{+}(0 \%$ de saturação de $\mathrm{Al}^{3+}$ ). Esse dado é importante, quando se observa a competição catiônica dos metais pelos sítios de adsorção do solo e entre elementos com maior valência.

Para diagnosticar a disponibilidade de metais pesados nos solos, diversos extratores têm sido utilizados, dentre esses, destacam-se a solução ácida de Mehlich-1 e do agente complexante DTPA (ANJOS \& MATTIAZZO, 2001; ABREU et al., 2002), que foram utilizados no presente estudo. O princípio de atuação do extrator DTPA é fundamentado na capacidade de combinação dos agentes complexantes com o íon metálico na solução do solo e com a constante de estabilidade termodinâmica do metal complexado (ABREU et al., 1998). O extrator Mehlich-1, por se tratar de uma solução diluída, remove metais em formas trocáveis da fase sólida, da solução e parte dos complexados (ABREU et al., 2002). Ao verificar os resultados expressos na tabela 3, foi constatado que o extrator Mehlich-1 apresentou-se como o mais apropriado para a determinação da fração trocável (biodisponível) do solo (principalmente para as plantas), por detectar maiores teores em praticamente todos os metais de interesse.

$\mathrm{Na}$ determinação dos teores pseudo-totais foi utilizado a mistura ácida água régia como protocolo analítico. Embora a água régia não seja considerada como um método capaz de fornecer o teor total de metais pesados, admite-se que esse método forneça uma estimativa razoável da quantidade máxima que poderá estar disponível para as plantas ou ser lixiviada para a água subterrânea (DIAZ-BARRIENTOS et al, 1991).

Na tabela 3 podem ser observados as concentrações recuperadas dos metais pesados no solo, utilizando o método da água régia como extrator químico. Os resultados indicaram que as concentrações dos elementos cobre, cromo, cádmio e chumbo estão acima dos valores orientadores de referência e prevenção estabelecidos pela Companhia de Tecnologia e Saneamento Ambiental (CETESB, 2005) para o Estado de São Paulo. Por outro lado, os elementos zinco e níquel apresentaram teores somente acima dos valores orientadores de referência prescritos pela mesma companhia acima citada. 
Tabela 3 - Teores de metais pesados biodisponíveis e pseudo-totais do solo utilizado:

\begin{tabular}{|c|c|c|c|c|c|c|c|}
\hline Método & $\mathrm{Cu}$ & $\mathrm{ZN}$ & $\mathrm{Cr}$ & Co & $\mathrm{Ni}$ & $\mathrm{Cd}$ & $\mathrm{Pb}$ \\
\hline \multicolumn{8}{|c|}{ Teores biodisponíveis (mg. $\mathrm{kg}^{-1}$ ) } \\
\hline DTPA & 3,1 & 1,5 & $<$ L.D. & $<$ L.D. & < L.D. & < L.D. & 3,0 \\
\hline MEHLICH-1 & 13,0 & 6,5 & 0,3 & 0,4 & 1,5 & < L.D. & 5,5 \\
\hline \multicolumn{8}{|c|}{ Teores pseudo-totais $\left(\mathrm{mg} \mathrm{kg}^{-1}\right.$ ) } \\
\hline ÁGUA RÉGIA & 107,6 & 73,8 & 86,4 & 9,03 & 22,5 & 4,7 & 79,1 \\
\hline \multicolumn{8}{|c|}{ Valores Orientadores para solo no Estado de São Paulo (mg.kg $\left.{ }^{-1}\right)$ - (CETESB, 2005) } \\
\hline Valor & $\mathrm{Cu}$ & ZN & $\mathrm{Cr}$ & Co & $\mathrm{Ni}$ & $\mathrm{Cd}$ & $\mathrm{Pb}$ \\
\hline Referência & 35 & 60 & 40 & 13 & 13 & $<0,5$ & 17 \\
\hline Prevenção & 60 & 300 & 75 & 25 & 30 & 1,3 & 72 \\
\hline Agrícola & 200 & 450 & 150 & 35 & 70 & 3 & 180 \\
\hline Residencial & 400 & 1.000 & 300 & 65 & 100 & 8 & 300 \\
\hline Industrial & 600 & 2.000 & 400 & 90 & 130 & 20 & 900 \\
\hline
\end{tabular}

\section{POTENCIAL FITORREMEDIADOR DAS ESPÉCIES VEGETAIS}

\section{PRODUÇÃO DE MASSA SECA}

No que se refere ao comportamento das espécies vegetais cultivadas nos solos contaminados, a análise de variância apresentada na tabela 4 demonstrou que as fontes de variações estudadas, bem como as interações, foram altamente significativas $(p \leq 0,01)$ na análise da produção biomassa seca (parte aérea, colmo e sistema radicular) gerada pelas espécies após o período de plantio.

Tabela 4: Resumo da análise de variância da produção da biomassa seca ( $\mathrm{g} \mathrm{planta}^{-1}$ ) das diferentes espécies vegetais após o período de plantio:

\begin{tabular}{|c|c|c|}
\hline Análise de Variância & Grau de Liberdade & Massa Seca \\
\hline Espécie & 4 & ${ }^{* *}$ \\
\hline Segregação & 2 & $* *$ \\
\hline Espécie * Segregação & 8 & - \\
\hline Erro & 45 & - \\
\hline CV (\%) & 32,82 & \\
\hline \multicolumn{2}{|c|}{} \\
\end{tabular}

Ao observar a figura 1 constatou-se, a partir da avaliação da produção de massa seca, que as espécies estudadas apresentaram um comportamento distinto em relação à presença dos contaminantes no solo. Dentre as espécies investigadas, o milho foi a que apresentou uma produção de biomassa (parte aérea e colmo) mais significativa. Já as espécies de algodão e girassol foram as que obtiveram uma produção de biomassa menos significativa. Com relação à geração de massa seca no sistema radicular não ocorreram diferenças estatísticas entre as espécies avaliadas.

$\mathrm{Na}$ literatura podem ser observados alguns estudos que apontam comportamentos distintos de espécies vegetais em relação à contaminação do solo, no que se refere à produção de biomassa. MARQUES et al. (2000), por exemplo, constataram em sua pesquisa que a produção de matéria seca da parte aérea das espécies estudadas foi muito influenciada pela contaminação do solo por metais pesados, sendo o impacto desse fator diferenciado entre as espécies. 
MARQUES (2009) citando TAIZ \& ZEIGER (2009) reporta que a produção de biomassa está associada à tolerância da espécie ao contaminante, conseguida através de diferentes adaptações bioquímicas que permitem à planta tolerar concentrações elevadas desses elementos. Essa tolerância pode ser conseguida através da redução do transporte através da membrana, exclusão, formação de peptídeos ricos em grupos tiólicos (fitoquelatinas e metalotioneínas), quelação por ácidos orgânicos e aminoácidos e principalmente a compartimentalização de metal em estruturas subcelulares, como vacúolos.

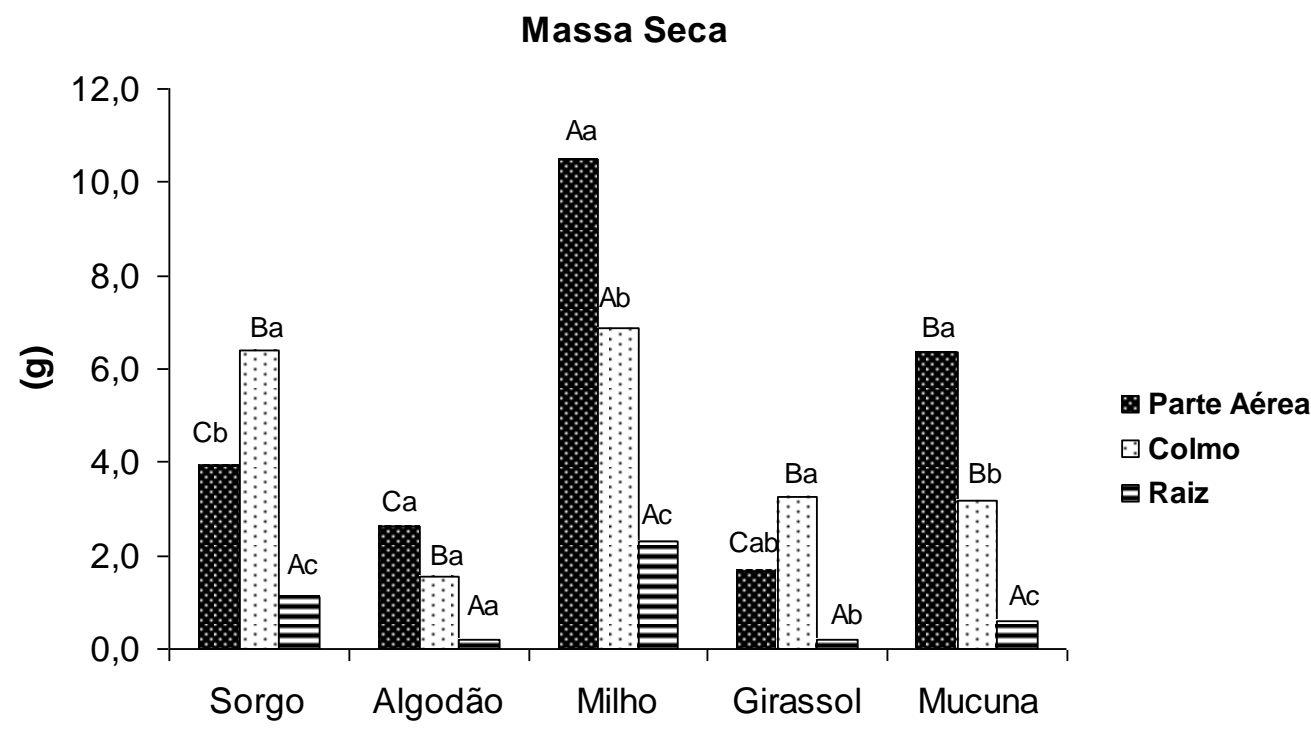

Figura 1: Produção da biomassa seca $\left(\mathrm{g} \mathrm{planta}^{-1}\right.$ ) das diferentes espécies vegetais após o período de plantio. Letras maiúsculas diferentes significam diferenças estatísticas entre as espécies e letras minúsculas diferentes significam diferenças estatísticas entre a segregação de cada espécie. $(P \leq 0,05)$.

\section{POTENCIAL FITOEXTRATOR DAS ESPÉCIES}

Na determinação dos teores e conteúdos de metais pesados presentes nas diferentes partes das plantas, constatou-se que as espécies estudadas apresentam comportamento distinto quanto absorção, transporte e acúmulo desses elementos em seus tecidos. Na tabela 5 pode ser visualizada a análise de variância que analisou o teor dos metais de interesse no tecido dos vegetais. A parir dessa análise foi verificado que somente os metais cobre, zinco e cromo foram fitoextraídos pelas espécies. Para esses metais, pode-se observar uma significância a nível de $1 \%$ de probabilidade em praticamente todas as fontes de variação do teste, tanto para as fontes isoladas, como para as interações duplas.

Tabela 5: Resumo da análise de variância da concentração dos metais pesados de interesse nas diferentes partes (parte aérea e colmo) das espécies vegetais após o período de plantio.

\begin{tabular}{|c|c|c|c|c|c|c|c|}
\hline $\begin{array}{c}\text { Análise de } \\
\text { Variância }\end{array}$ & $\mathrm{GL}$ & $\mathrm{Cu}$ & $\mathrm{Zn}$ & $\mathrm{Cr}$ & $\mathrm{Co}$ & $\mathrm{Ni}$ & $\mathrm{Cd}$ \\
\hline Espécie & 4 & $* *$ & $* *$ & $* *$ & - & - & - \\
\hline Segregação $^{*}$ & 1 & n.s. & $* *$ & $* *$ & - & - \\
\hline $\begin{array}{c}\text { Espécie } \\
\text { Segregação }\end{array}$ & 4 & $*$ & $* *$ & $* *$ & - & - & - \\
\hline Erro & 30 & - & - & - & - & - \\
\hline CV (\%) & - & 29,21 & 22,20 & 45,33 & - & - & - \\
\hline
\end{tabular}


Concentrações dos elementos cobalto, níquel, cádmio e chumbo não foram detectadas nas diferentes partes das plantas. Conforme descrito por TAVARES (2009), esse fato ocorre devido na maioria das vezes à absorção dos metais pelas plantas ser limitada pela baixa solubilidade e difusão destes no solo e para a superfície das raízes. Portanto, torna-se importante neste contexto, o uso de agentes complexantes, a fim de aumentar a absorção dos metais pelas plantas e facilitar o processo de fitorremediação.

Um fato importante ao avaliar a eficiência de cada espécie em absorver os metais pesados em excesso no solo é avaliar a quantidade retida em relação à matéria seca da planta. Por esta razão, GREGER (2003) afirma que as plantas hiperacumuladoras possuem baixa produção de biomassa e alta acumulação de metais e que as plantas acumuladoras produzem mais biomassa, mas acumulam menos metal em relação às hiperacumuladoras. A razão para diferenciá-las é o fato de que somente a acumulação do metal não é importante, mas também a biomassa que a espécie produz, pois a extração por área é o resultado pretendido. Conforme descrito por WATANABE (1997), uma boa planta hiperacumuladora deve ter como características: alta taxa de acumulação mesmo em baixas concentrações do contaminante; capacidade concomitante de acúmulo de diversos contaminantes; alta taxa de crescimento e de produção de biomassa; resistência a pragas e doenças; capacidade de absorção e concentração e tolerância ao contaminante.

Com base nos resultados da tabela 6, verifica-se que o sorgo e o milho, dentre as espécies avaliadas, foram as mais eficazes em fitoextrair os metais pesados (cobre, zinco e cobre). Mesmo em baixas concentrações desses elementos no solo as espécies foram capazes de absorver quantidades significativas desses metais. Fato similar foi observado por ZEITOUNI (2003) em seu estudo. Esse autor ao avaliar a fitoextração dos metais zinco e cobre em solos pouco contaminados, na presença e ausência do quelante EDTA, utilizando as espécies de mamona, tabaco, girassol e pimenta, constatou que o girassol foi à espécie mais eficiente em remover o $\mathrm{Cu}$, principalmente utilizando o quelante EDTA. Para o metal zinco, o autor também verificou uma maior eficácia do girassol, contudo diferentemente do que ocorreu com o cobre a fitoextração se mostrou melhor na ausência do quelante.

Tabela 6: Teor dos metais pesados de interesse na biomassa das espécies após o plantio*:

\begin{tabular}{|c|c|c|c|c|c|c|c|}
\hline Espécie & $\mathrm{Cu}$ & $\mathrm{Zn}$ & $\mathrm{Cr}$ & Co & $\mathrm{Ni}$ & $\mathrm{Cd}$ & $\mathrm{Pb}$ \\
\hline \multicolumn{8}{|c|}{ mg.vaso $^{-1}$} \\
\hline Sorgo & $0,0668 a$ & $0,2528 a$ & $0,0279 a$ & <L.D. & <L.D. & <L.D. & $<$ L.D. \\
\hline Algodão & $0,0132 b$ & $0,0397 d$ & <L.D. & <L.D. & <L.D. & <L.D. & $<$ L.D. \\
\hline Milho & $0,0584 a$ & $0,1676 b$ & $0,0322 a$ & <L.D. & <L.D. & <L.D. & $<$ L.D. \\
\hline Girassol & $0,0266 b$ & $0,0759 \mathrm{~cd}$ & $0,0016 b$ & <L.D. & <L.D. & <L.D. & $<$ L.D. \\
\hline Mucuna & $0,0541 a$ & $0,1386 b c$ & <L.D. & $<$ L.D. & <L.D. & <L.D. & $<$ L.D. \\
\hline
\end{tabular}

*Médias seguidas de mesma letra nas colunas não diferem entre si, pelo teste de Tukey $(P \leq 0,05)$.

No presente estudo, embora as espécies tenham sido segregadas em parte aérea, colmo e sistema radicular, não foi possível detectar as concentrações dos metais pesados nesse último compartimento das plantas, devido à produção de biomassa seca ser muito baixa, impossibilitando a realização das análises. Deste modo, serão discutidos somente os resultados referentes aos teores verificados na parte aérea e colmo das plantas.

De acordo com as figuras 2, 3 e 4, observa-se que as espécies apresentaram um comportamento distinto na translocação do metal cobre para os seus compartimentos. Para as espécies algodão e o girassol os teores encontrados no colmo e na parte aérea não apresentaram 
diferenças estatísticas. Por outro lado, o milho e a mucuna acumularam a maior parte dos metais cobre e zinco na parte aérea, enquanto o sorgo absorveu maiores quantidades no colmo. Somente para o elemento cromo, a espécie de milho absorveu uma quantidade mais significativa do metal no compartimento colmo. Conforme destacado por ACCIOLY \& SIQUEIRA (2000), as plantas exibem comportamento diferenciado em relação à absorção e translocação dos metais das raízes para a parte aérea e, por isso, possuem teores diferenciados nas diferentes partes. A distribuição dos metais absorvidos nos diferentes órgãos da planta é também muito diferenciada. Portanto, esse aspecto precisa ser conhecido nas espécies destinadas a programas de remediação.

\section{$\mathrm{Cu}$}

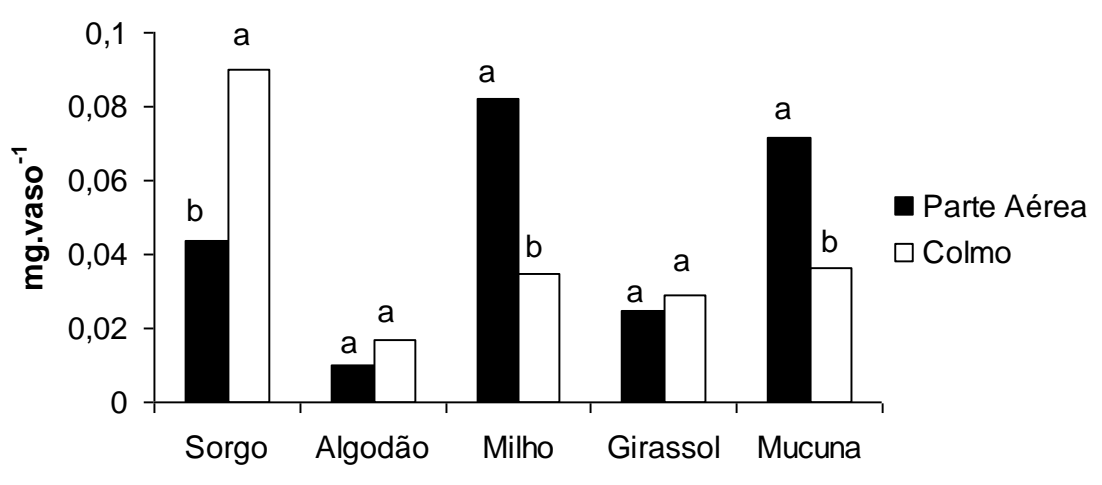

Figura 2: Teor de cobre na biomassa das espécies após o período de plantio. Letras minúsculas diferentes significam diferenças estatísticas na segregação (parte aérea e colmo) de cada espécie pelo teste Tukey $(P \leq 0,05)$.

$\mathrm{Zn}$

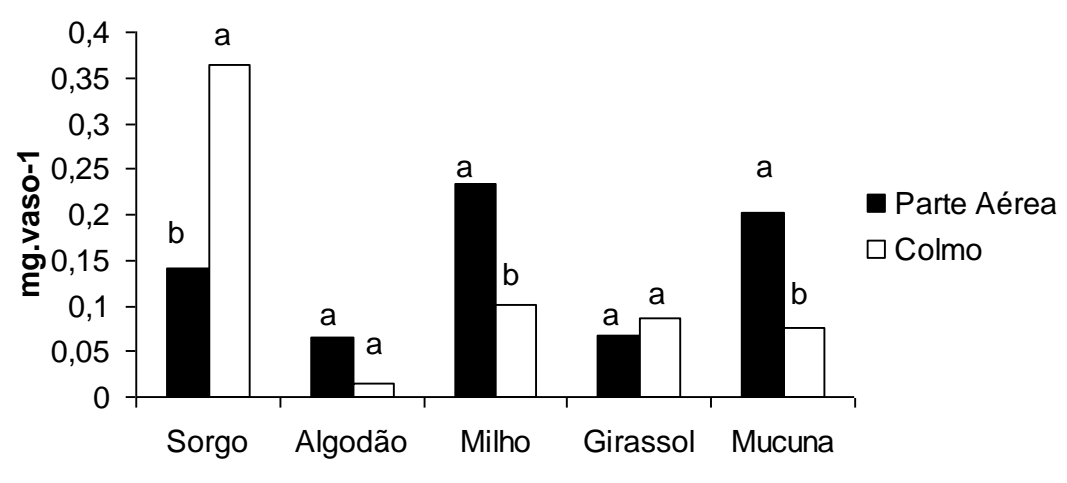

Figura 3: Teor de zinco na biomassa das espécies após o período de plantio. Letras minúsculas diferentes significam diferenças estatísticas na segregação (parte aérea e colmo) de cada espécie pelo teste Tukey $(P \leq 0,05)$. 


\section{$\mathrm{Cr}$}

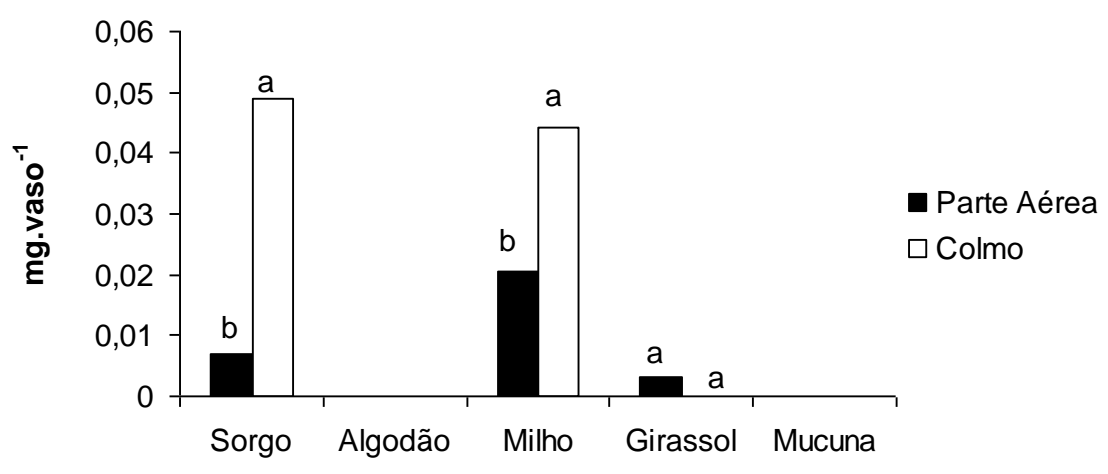

Figura 4: Teor de cromo na biomassa das espécies após o período de plantio.

Letras minúsculas diferentes significam diferenças estatísticas na segregação (parte aérea e colmo) de cada espécie pelo teste Tukey $(P \leq 0,05)$.

\section{CONCENTRAÇÃO DE METAIS PESADOS NO SOLO APÓS O PERÍODO DE PLANTIO}

Conforme pode ser observado na tabela 7, somente para o elemento cobre as espécies exerceram influência na determinação do teor pseudo-total do metal depois de transcorrido o período de plantio. Essa significância ficou a nível de $5 \%$ de probabilidade. Para os demais metais avaliados não ocorreram diferenças estatísticas significativas.

Tabela 7: Resumo da análise de variância das concentrações pesudo-totais dos metais pesados de interesse no solo após o período de plantio das espécies vegetais.

\begin{tabular}{|c|c|c|c|c|c|c|c|c|}
\hline $\begin{array}{c}\text { Análise de } \\
\text { Variância }\end{array}$ & $\mathrm{GL}$ & $\mathrm{Cu}$ & $\mathrm{Zn}$ & $\mathrm{Cr}$ & $\mathrm{Co}$ & $\mathrm{Ni}$ & $\mathrm{Cd}$ & $\mathrm{Pb}$ \\
\hline Espécie & 4 & $*$ & $\mathrm{n} . \mathrm{s}$ & $\mathrm{n} . \mathrm{s}$ & $\mathrm{n} . \mathrm{s}$ & $\mathrm{n} . \mathrm{s}$ & $\mathrm{n} . \mathrm{s}$ & $\mathrm{n} . \mathrm{s}$ \\
\hline Erro & 19 & & & & & & & \\
\hline $\mathrm{CV}(\%)$ & & 21,79 & 6,04 & 51,19 & 125,86 & 8,35 & 7,80 & 12,42 \\
\hline
\end{tabular}

Ao verificar a tabela 8 notou-se que no solo onde foi cultivada a espécie de girassol ocorreu uma maior redução na concentração pseudo-total do metal. Esses dados diferem dos encontrados para os teores verificados na parte aérea e colmo, pois foram às espécies de milho, sorgo e mucuna que apresentaram uma maior capacidade de absorver o elemento. Contudo, cabe mencionar que o teor fitoextraído pelo sistema radicular não foi determinado analiticamente, logo se presume que o algodão tenha absorvido maiores quantidades do elemento nesse compartimento da planta.

Com relação aos teores biodisponíveis, constatou-se que as espécies exerceram influencia na disponibilidade dos metais cromo, níquel e chumbo para o ambiente, conforme pode ser observado na tabela 9, onde a análise de variância indicou diferenças estatísticas a níveis de 1 e $5 \%$ de probabilidade. Entre os extratores utilizados no estudo também foram verificadas diferenças significativas na recuperação dos metais de interesse. 
Tabela 8: Concentração pseudo-total dos metais pesados de interesse no solo após o período de plantio:

\begin{tabular}{|c|c|c|c|c|c|c|c|}
\hline Espécie & $\mathrm{Cu}$ & $\mathrm{Zn}$ & $\mathrm{Cr}$ & $\mathrm{Co}$ & $\mathrm{Ni}$ & $\mathrm{Cd}$ \\
\hline \multicolumn{7}{|c|}{$\mathrm{mg.kg}{ }^{-1}$} \\
\hline T0* & 107,00 & 73,80 & 86,40 & 9,30 & \multicolumn{2}{|c|}{22,50} & 4,70 \\
\hline Sorgo & $33,09 \mathrm{ab}$ & $43,45 \mathrm{a}$ & $52,81 \mathrm{a}$ & $0,00 \mathrm{a}$ & $15,80 \mathrm{a}$ & $4,25 \mathrm{a}$ & 34,10 \\
\hline Algodão & $29,41 \mathrm{ab}$ & $45,92 \mathrm{a}$ & $52,57 \mathrm{a}$ & $3,89 \mathrm{a}$ & $16,11 \mathrm{a}$ & $4,43 \mathrm{a}$ & $33,29 \mathrm{a}$ \\
\hline Milho & $26,52 \mathrm{ab}$ & $42,11 \mathrm{a}$ & $48,28 \mathrm{a}$ & $0,00 \mathrm{a}$ & $14,29 \mathrm{a}$ & $4,22 \mathrm{a}$ & $28,97 \mathrm{a}$ \\
\hline Girassol & $23,16 \mathrm{c}$ & $43,93 \mathrm{a}$ & $50,66 \mathrm{a}$ & $0,00 \mathrm{a}$ & $16,22 \mathrm{a}$ & $4,47 \mathrm{a}$ & $28,62 \mathrm{a}$ \\
\hline Mucuna & $37,19 \mathrm{a}$ & $42,54 \mathrm{a}$ & $51,61 \mathrm{a}$ & $0,00 \mathrm{a}$ & $14,39 \mathrm{a}$ & $4,22 \mathrm{a}$ & $35,16 \mathrm{a}$ \\
\hline
\end{tabular}

Médias seguidas de mesma letra nas colunas não diferem entre si, pelo teste de Tukey 0,05.

* T0 (Concentração antes do plantio das espécies).

Tabela 9: Resumo da análise de variância das concentrações biodisponíveis dos metais pesados de interesse no solo após o período de plantio das espécies vegetais:

\begin{tabular}{|c|c|c|c|c|c|c|c|}
\hline $\begin{array}{c}\text { Análise de } \\
\text { Variância }\end{array}$ & $\mathrm{GL}$ & $\mathrm{Cu}$ & $\mathrm{Zn}$ & $\mathrm{Cr}$ & $\mathrm{Co}$ & $\mathrm{Ni}$ & $\mathrm{Cd}$ \\
\hline Espécie & 4 & n.s. & n.s. & $* *$ & n.s. & $*$ & - \\
\hline Extrator & 1 & $* *$ & $* *$ & $* *$ & $* *$ & $* *$ & $*$ \\
\hline Espécie Extrator & 4 & n.s. & n.s. & $* *$ & $*$ & $*$ & - \\
\hline Erro & 30 & & & & & & $*$ \\
\hline CV (\%) & & 40,22 & 18,05 & 25,72 & 170,51 & 58,03 & - \\
\hline
\end{tabular}

Ao observar os teores biodisponíveis dos metais pesados sob investigação, constata-se que o extrator Mehlich-1 foi mais eficiente em recuperar os metais. Para o extrator DTPA foram observadas diferenças estatísticas somente na detecção do metal chumbo, onde pode ser verificado que no solo em que foi cultivada a espécie de girassol o teor biodisponível do metal foi reduzido, sendo o mesmo comportamento observado com o extrator Mehlich-1.

Para o elemento cobre, assim como ocorreu na detecção do teor pseudo-total, o girassol foi à espécie mais eficaz em diminuir as frações biodisponível do metal. Essa espécie também foi eficiente em capturar os elementos cromo e níquel, tendo como base os níveis desses metais biodisponíveis no solo após o plantio das espécies vegetais, como pode ser observado na tabela 10.

Tabela 10: Concentrações biodisponíveis dos metais pesados de interesse no solo após o período de plantio:

\begin{tabular}{|c|c|c|c|c|c|c|c|}
\hline Espécie & $\mathrm{Cu}$ & $\mathrm{Zn}$ & $\mathrm{Cr}$ & Co & $\mathrm{Ni}$ & $\mathrm{Cd}$ & $\mathrm{Pb}$ \\
\hline \multicolumn{8}{|c|}{ DTPA mg.kg ${ }^{-1}$} \\
\hline TO & 3,10 & 1,50 & $<$ L.D. & <L.D. & <L.D. & <L.D. & 3,00 \\
\hline Sorgo & $2,51 \mathrm{a}$ & $1,25 \mathrm{a}$ & $<$ L.D. & $<$ L.D. & $0,53 \mathrm{a}$ & $<$ L.D. & $2,68 a b$ \\
\hline Algodão & $2,13 \mathrm{a}$ & $1,19 \mathrm{a}$ & <L.D. & $<$ L.D. & <L.D. & <L.D. & $2,39 a b$ \\
\hline Milho & $2,22 \mathrm{a}$ & $1,13 \mathrm{a}$ & $<$ L.D. & $<$ L.D. & $<$ L.D. & $<$ L.D. & $2,43 a b$ \\
\hline Girassol & $1,43 \mathrm{a}$ & $1,06 \mathrm{a}$ & $<$ L.D. & <L.D. & <L.D. & <L.D. & $1,50 \mathrm{~b}$ \\
\hline Mucuna & $2,75 \mathrm{a}$ & $1,10 \mathrm{a}$ & <L.D. & <L.D. & $0,05 \mathrm{a}$ & <L.D. & $3,24 \mathrm{a}$ \\
\hline \multicolumn{8}{|c|}{ MEHLICH mg.kg ${ }^{-1}$} \\
\hline T0 & 13,00 & 6,50 & 0,30 & 0,40 & 1,50 & $<$ L.D. & 5,50 \\
\hline Sorgo & $11,19 \mathrm{ab}$ & $5,47 \mathrm{a}$ & $0,24 \mathrm{bc}$ & <L.D. & $0,68 a b$ & <L.D. & $4,75 a$ \\
\hline Algodão & $10,76 \mathrm{ab}$ & $5,27 \mathrm{a}$ & $0,21 \mathrm{~cd}$ & <L.D. & $0,47 a b$ & <L.D. & 4,59 a \\
\hline Milho & $10,57 a b$ & $4,99 a$ & $0,28 \mathrm{ab}$ & 0,15 a & $0,71 a b$ & <L.D. & $5,49 \mathrm{a}$ \\
\hline Girassol & $6,41 \mathrm{c}$ & $4,67 a$ & $0,16 \mathrm{~d}$ & $0,07 a b$ & $0,32 \mathrm{~b}$ & <L.D. & $2,65 b$ \\
\hline Mucuna & $12,72 \mathrm{a}$ & $4,82 \mathrm{a}$ & $0,31 \mathrm{a}$ & $0,092 a b$ & $0,90 \mathrm{a}$ & <L.D. & $4,50 \mathrm{a}$ \\
\hline
\end{tabular}

Médias seguidas de mesma letra nas colunas não diferem entre si, pelo teste de Tukey 0,05.

* T0 (Concentração antes do plantio das espécies). 


\section{CONCLUSÕES}

- As análises das propriedades químicas e físicas dos solos são necessárias para avaliação da contaminação, pois fornecem parâmetros que interferem diretamente na mobilidade do metal. Sendo assim, o estudo caso a caso torna-se uma medida mais apropriada na avaliação de áreas contaminadas e na estimativa das técnicas de remediação que podem ser executadas.

- A extração por água régia empregando o método de preparação da amostra com o uso do microondas, além ser mais rápida, mostrou-se adequada para a determinação das concentrações pseudo-totais dos metais, podendo ser indicada para o monitoramento ambiental.

- As soluções extratoras DTPA e Mehlich-1 se mostraram eficazes em avaliar a disponibilidade dos metais pesados presentes no solo.

- O girassol se destacou em relação às demais espécies em reduzir a concentração do metal cobre no solo, embora mais estudos devam ser realizados, visando aumentar a produção de biomassa e a translocação desse metal para parte aérea desta espécie.

- O milho foi a espécie que apresentou maior produção de biomassa seca e maior eficiência em translocar os metais cobre e zinco para a parte aérea.

- A remediação de solos contaminados por metais pesados utilizando a técnica de fitorremediação pode ser uma alternativa viável, pois além de recuperar a área contaminada promove a revegetação do local. Essa técnica é também considerada de baixo custo e de fácil implementação. Contudo, é necessário que mais estudos sejam realizados com intuito de reunir informações mais precisas sobre a capacidade fitorremediadora de cada espécie vegetal.

\section{REFERÊNCIAS BIBLIOGRÁFICAS}

1. ABREU, C.A.; ABREU, M.F.; BERTON, R.S., 2002, Análises químicas de solo para metais pesados. In: ALVAREZ, V.H.; SCHAEFER, C.F.G.R; BASTOS, N.F.; MELLO, J.W.V.;COSTA, L.M. (Ed). Tópicos em Ciência do Solo. Viçosa: Sociedade Brasileira de Ciência do Solo, v.2, pp. 645692.

2. ABREU, C. A.; ABREU, M. F.; ANDRADE, J. C., 1998, Distribuição de chumbo no perfil de solo avaliada pelas soluções de DTPA e Mehlich-3. Bragantia, Campinas, v. 57, n. 1, pp. 185-192.

3. ACCIOLY, A. M. A.; SIQUEIRA, J. O., 2000, Contaminação química e biorremediação do solo. In: NOVAIS, R. F. et al. (Eds.) Tópicos em ciência do solo. Viçosa-MG: Sociedade Brasileira de Ciência do Solo, v. 1. pp. 299-352.

4. ALLEONI, L.R.F.; BORBA, R.P.; CAMARGO, O.A., 2000, Metais pesados: da cosmogênese aos solos brasileiros. Tópicos em Ciência do Solo. Sociedade Brasileira de Ciência do Solo. Viçosa, MG, v. 1, pp 2-36.

5. ALLOWAY, B.J., 1990, Heavy metals in soils. New York; Wiley, 339p.

6. ALMEIDA, E.L.; MARCOS, F.C.C.; SCHIAVINATO, M.A.; LAGÔA, A.M.M.A. \& ABREU, M.F., 2008. Crescimento de feijão-de-porco na presença de chumbo. Bragantia, Campinas, v. 67, n. 3, pp. 569-576. 
7. ANDERSSON, A., 1977, The distribution of heavy metals in soils and soil material as influenced by the ionic radius. Swedish J. Agric. Res, 7, pp. 79-83.

8. ANDRADE, M. G.; MELO, V.F.; GABARDO, J. SOUZA, L.C.P.; REISSMANN, C.B., 2009, Metais pesados em solos de área de mineração e metalurgia de chumbo: I - Fitoextração. Revista Brasileira de Ciência do Solo, v.33, n.6, pp. 1879-1888.

9. ANDRADE, J.C. M; TAVARES, S.R.L; MAHLER, C.F., 2007, Fitorremediação: o uso de plantas na melhoria da qualidade ambiental. São Paulo. Oficina de Textos. 2007. 176p.

10. ANJOS, A.R.M. \& MATTIAZZO, M.E., 2001, Extratores para Cd, Cu, Cr, Mn, Ni, Pb e Zn em Latossolos tratados com biossólido e cultivado com milho. Sci. Agric, v.58, pp.337-344.

11. BAIRD, C., 2002, Química Ambiental. 2ed. Porto Alegre. Bookman, 622p.

12. BERTON, R S., 2000, Riscos de contaminação do agrossistema com metais pesados. In: BETTIOL, W.; CAMARGO O. A.(Ed.) Impacto Ambiental do uso agrícola do lodo de esgoto.EMBRAPA Meio Ambiente. Jaguariúna, SP,cap. 16.

13. BERROW, M.L. \& STEIN, W. M., 1983, Extraction of metals from soils and sludges by refluxing with aqua regia. Analyst, Cambridge, v.108, pp. 277-285.

14. CAMARGO, O.A.; ALLEONI, L.R.F; CASAGRANDE, J.C., 2001, Reações dos micronutrientes e elementos tóxicos. In: FERREIRA, M. E.; CRUZ, M.C.P. da VAN RAIJ, G.; ABREU, C.A de (Ed). Micronutrientes e elementos tóxicos na agricultura. Jaboticabal: CNPq/FAPESP/POTAFOS, cap 5, pp. 89-124.

15. COMPANHIA DE TECNOLOGIA DE SANAEMANTO AMBIENTAL, 2005, Relatório de estabelecimento de valores orientados para solos e águas subterrâneas no Estado de São Paulo. São Paulo: CETEBS, 247p.

16. DAVIES, B. E., 1995, Lead. In: ALLOWAY, B.J. (Ed.) Heavy metals in soils. Chapman \& Hall. 2aed. Reading, UK, cap. 9.

17. DIAZ-BARRIENTOS, E.; MADRID, L.; CABRERA, F.; CONTRERAS, M.C., 1991, Comparison of two methods of sample preparation for determination by atomic absorption spectrophotometry of heavy metals in soils and sediments. Communications in Soil Science and Plant Analysis, New York, v.22, n.15/16, pp.1559-1568.

18. ELLIOTT, H. A.; LIBERATI, M. R.; HUANG, C. P., 1986, Competitive adsorption of heavy metals by soils. Journal Environmental Quality, v. 15, pp. 214-217,

19. EMPRESA BRASILEIRA DE PESQUISA AGROPECUÁRIA - EMBRAPA, 2009, Manual de Métodos de Análise de Solo. Centro Nacional de Pesquisa de Solos. Rio de Janeiro, 3a ed, 212pp.

20. ESTADOS UNIDOS. Environmental Protection Agency. Office of Soild Waste and Emergency Response. Soil Screening Guidance. Technical Background Document. Washington.EPA, 1996. (EPA/540/R-95/128).

21. FERREIRA, D.F., 2000, Análises estatísticas por meio do Sisvar para Windows versão 4.0. In...45 Reunião Anual da Região Brasileira da Sociedade internacional de Biometria. UFSCar, São Carlos, SP, pp.255-258. 
22. GOMES, P.C; FONTES, M.P.F.; SILVA, A.G; MENDONÇA, E.S.; NETTO, A.R., 2001, Selectivity sequence and competitive adsorption of heavy metals by Brazilian soils. Soil Science Society of American Journal, v.65, pp. 1115-1121.

23.GOMES, P.C., 1996, Fracionamento e biodisponibilidade de metais pesados influenciados por calagem e concentrações de metais em Latossolo Vermelho-Amarelo. Tese de Doutorado. Universidade Federal de Viçosa -UFV. Viçosa. 161pp.

24. GARBISU, C.; ALKORTA, I., 2001, Phytoextraction: a cost effective plant-based technology for the removal of metals from the environment. Bioresource Technology, v. 77, pp. $229-236$.

25. GREGER, M., 2003, Phytoremediation - Does it work? In: INTERNATIONAL CONFERENCE ON THE BIOGEOCHEMESTRY OF TRACE ELEMENTS, 7., 2003, Uppsala-Sweden: SLU Service, pp.1011.

26. KABATA -PENDIAS, A.; PENDIAS, H., 2001, Trace elements in soils and plants. 3 ed. Boca Raton, Flórida, CRC Press, 331pp.

27. LEMOS, R.C. \& SANTOS, R.D., 1984, Manual de descrição e coleta de solo no campo. 2.ed. Campinas: Sociedade Brasileira de Ciência do Solo; Embrapa-SNLCS, 46pp.

28. LINDSAY, W. L. \& NORVELL, W. A., 1978, Development of a DTPA soil test for zinc, irion, manganese and copper. Soil Sci. Am. J., v. 42, pp 421-428.

29. McBRIDE, M. B., 1994, Environmental chemistry of soils. New York, Oxford, 406 pp.

30. McBRIDE, M.B. \& BLASIAK, J.J., 1979, Zinc and copper solubility as a function of pH in an acid soil, Soil Science Society of America Journal, v.43, pp.866-870.

31. McGRATH, S.P., 1998, Phytoextraction for soil remediation. In: Brooks, R.R (Ed), Plants that Hyperaccumulate Heavy Metals, CAB International, Wallingford, pp.261.

32. McGRATH, S.P.; SHEN, Z.G.; ZHAO, F.J., 1994, Heavy metal uptake and chemical changes in the rhizosphere of Thlaspi caerulescens and Thlaspi ochroleucum grown in contaminated soils. Plant Soil., v. 188, pp. 153-159.

33. McLAUGHLIN, M.J.; ZARCINAS,B.A.; STEVENS, D.P. \& COOK, N., 2000, Soil Testing for heavy metals. Communication in Soil Science and Plant Analysis, v.31, pp.1661-1700.

34. MARQUES, L.F., 2009, Fitoextração de chumbo por girassol, vetiver, trigo mourisco, jureminha e mamona em áreas contaminadas. Dissertação de mestrado. Universidade Federal da Bahia, 48pp.

35. MARQUES, T.C.L.S.M.; SIQUEIRA, J.O.; MOREIRA, F.M.S., 2000, Crescimento e teor de metais de mudas de espécies arbóreas cultivadas em solo contaminado com metais pesados. Pesq. Agrop. Bras., v. 35, n. 1, pp. 121-132.

36. MATTIGOD, S. V., G. SPOSITO, A. L., apud, MCLEAN, J.E.; BLEDSOE, B.E. Behavior of metals in soil. In: USEPA, office of waste an emergency response and office of research and development. Washington DC: Ground Water Issue, 1992. 540-S92-018. Disponível em: www.epa.gov/tio/tsp/download/issue14.pdf (acesso 20/03/2010).

37. MAVROPOULOS, E., 1999, A hidroxiapatita como absorvedor de metais. Tese de Mestrado. Fundação Oswaldo Cruz, Escola Nacional de Saúde Pública; 1999. 105 p.

38. MEHLICH, A., 1953, Determination of P, Ca, Mg, K, Na and NH4. North Carolina Soil Test 
Division. Raleigh, North Carolina, 1953. (mimeografado).

39. NRIAGU J.O. \& NIEBOER E. (Eds.), 1988. Chromium in the Natural and Human Environments. John Wiley \& Sons, New York, 571 pp.

40. NOVOTNH, V., 1995, Diffuse Sources of Pollution by Toxic Metals and Impact on Receiving Water. In: SOLOMONS, W.; FORSTNER, U. Heavy Metals: Problems and Solution. Berlim. Springer. 1995. 33-53.

41. SOARES, M.R., 2004, Coeficiente de distribuição (Kd) de metais pesados em solos de São Paulo. Tese de Doutorado. São Paulo. Escola Superior de Agricultura Luiz de Queiroz, 214pp.

42. SOARES, C.F.F.S; ACCIOLY, A.M.A.; SIQUEIRA, J.O.; MOREIRA, F.M.S., 2000, Diagnóstico e reabilitação de áreas degradada pela contaminação por metais pesados. In: Simpósio Nacional Sobre Recuperação de Áreas Degradadas: Água e Biodiversidade. Belo Horizonte. Sociedade Brasileira de Recuperação de Áreas degradadas, pp. 56-82.

43. SPARKS, D.L., 1995, Environmental soil chemistry. San Diego. Academic press, 267pp.

44. SPOSITO, G. The chemistry of soils. New York: Oxford, 1984. 277 p.

45. STEVENSON, F.J., 1982, Humus Chemistry. New York, John Wiley, 443pp.

46. TAVARES, S.R.L., 2009, Fitorremediação em solo e água de áreas contaminadas por metais pesados provenientes da disposição de resíduos perigosos. Tese de Doutorado. Universidade Federal do Rio de Janeiro, Rio de Janeiro, RJ, Brasil, 371pp.

47. WATANABE, M.E., 1997, Phytoremediation on the brink of commercialization. Environmenta ScienceTechnology,v.31, p.182-186.

48. ZEITTOUNI, C. F.; BERTON, R. S. \& ABREU, C. A., 2007, Fitoextração de cádmio e zinco de um latossolo vermelho-amarelo contaminado com metais pesados. Bragantia v. 66, n.4, pp. 649-657.

49. ZEITOUNI, C.F., 2003, Eficiência de espécies vegetais como fioextratoras de cádmio, chumbo, cobre, níquel e zinco de um Latossolo Vermelho Amarelo Distrófico. Dissertação de Mestrado em Agricultura Tropical e Subtropical / Gestão de Recursos Agroambientais. Instituto Agronômico de Campinas - IAC. Campinas, SP, Brasil, 91pp. 